\title{
Disability Measurement in Patients with Low Back Pain Using Roland-Morris Questionnaire as a Model and Studying Possible Modifications
}

\author{
Dr. Ismail D. Saeed ${ }^{a}$, Dr. Ali F. Y. Al-Barodchib \\ ${ }^{a}$ Department of Medicine, College of Medicine, University of Mosul, Mosul, ${ }^{b}$ The Rheumatology Outpatient Clinic, Ibn \\ Sena Teaching Hospital, Mosul, Iraq. Correspondence: Ismail D. Saeed. medicine.ismael@gmail.com.
}

(Ann Coll Med Mosul 2019; 41 (1):18-27).

Received: 17 $7^{\text {th }}$ Feb. 2019; Accepted: $16^{\text {th }}$ Apr. 2019.

\begin{abstract}
Background: Self-reported questionnaires have become popular measures in assessing disability in patients with low back pain (LBP). Roland-Morris Questionnaire (RMQ) is one of the internationally accepted, self-reporting questionnaire which demonstrates good psychometric properties.

Objectives: The present study intended to evaluate a face to face interview applying Arabic version of the $R M Q$, and comparing it with a modified version of RMQ (RMQV), and whether the purely subjective RMQ scores correlate with symptoms and signs which have predictive or prognostic values.

Design: case-series study

Methods and materials: Case-series study conducted on seventy-two patients with chronic LBP at Ibn-Sina Teaching Hospital in Mosul city. Physical examination at rheumatology outpatient clinic performed for every patient, and the patients are allowed to answer the questions of RMQ through a direct investigator-patient Arabic conversation. The disability measured by the RMQ subdivided into: mild (0-8), moderate (9-16) and severe (17-24). An individualized literature review performed for clinical features which have predictive or prognostic values in LBP, and including these features in the clinical evaluation of patients in the current study.

Results: The results showed that the Arabic conversational RMQ have acceptable reliability and RMQV have excellent reliability (Cronbach's alpha values $=0.72$ and 0.94 respectively). There was a significant direct correlation between these two questionnaires $(r=0.861 ; p$-value $<0.001)$. However, we found a significant difference between them ( $p$-value $<0.01)$. The scores of the RMQ and RMQV correlate moderately with a score of the predictive features $(r=0.503 ; p$-value $<0.01$ and $0.530 ; p$-value $<0.01$ respectively).

Conclusion: The study found that the modified version (RMQV) has higher reliability than the original one. Also, the RMQV showed a better correlation with the narrow-angle straight leg raising test, and its mild and moderate subgroups have significant differences regarding the duration and pain intensity of the current episode of LBP. Other measured properties look similar between the two questionnaires.
\end{abstract}

Keywords: Low back pain, disability measurement, Roland-Morris Questionnaire.

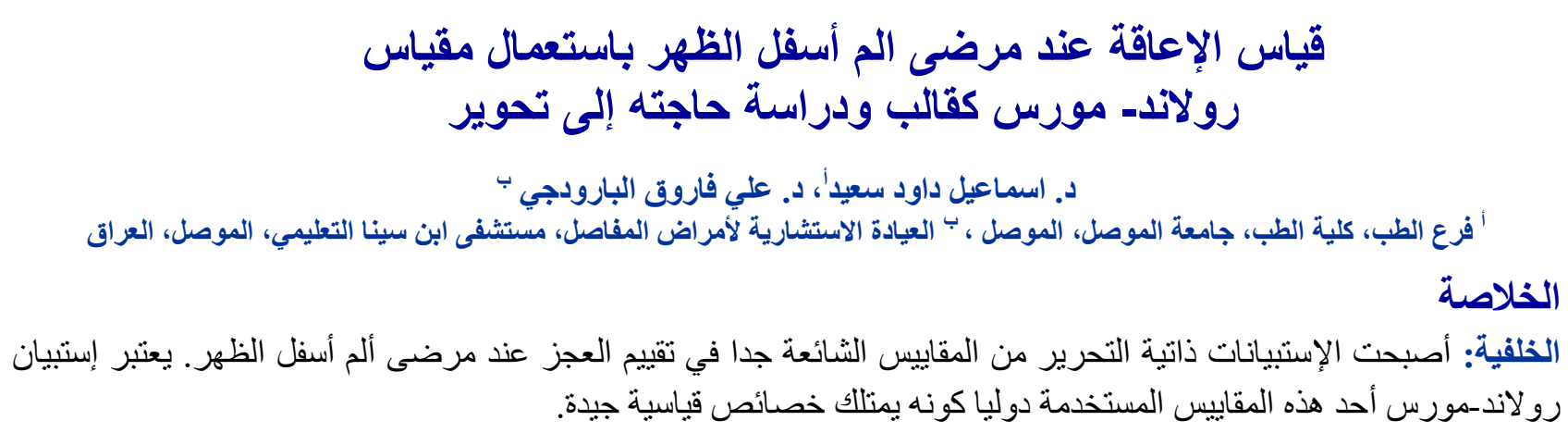




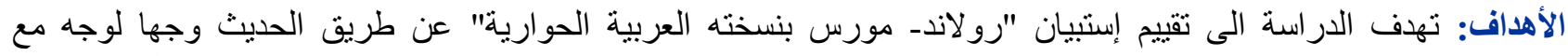

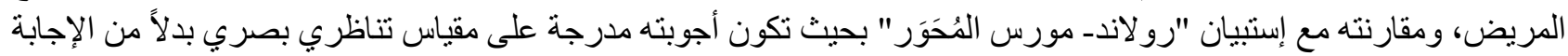

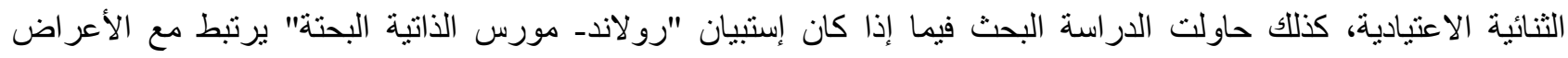
والعلامات ذات القيم التنبؤية. التصميم: در اسة سلسلة حالات. الطر ائق: أجريت الدر اسة على إثثين وسبعين مريضا ممن بعانون ألم أسفل الظهر المزمن وذلات ولك في مستشفى ابن سينا التعليمي في

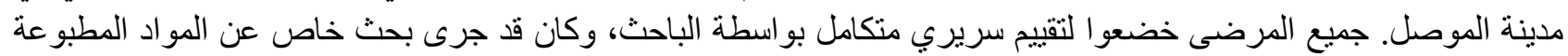

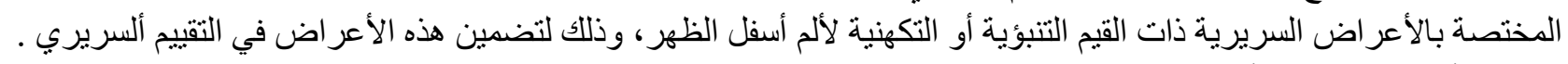

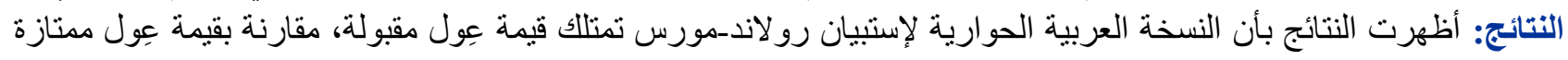

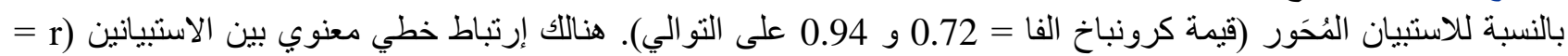

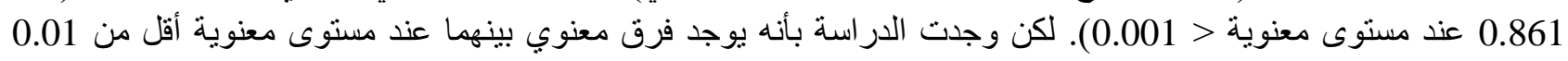

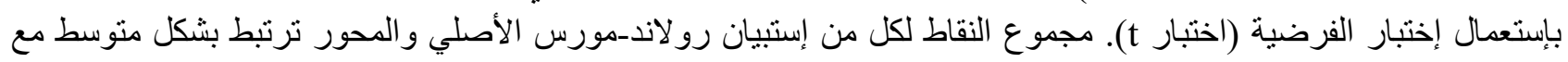

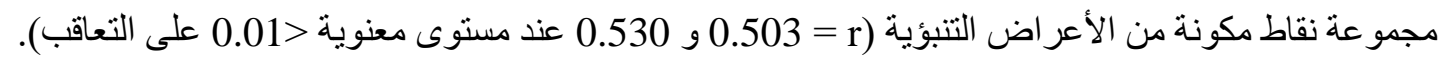

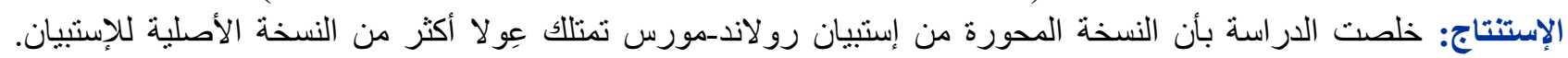

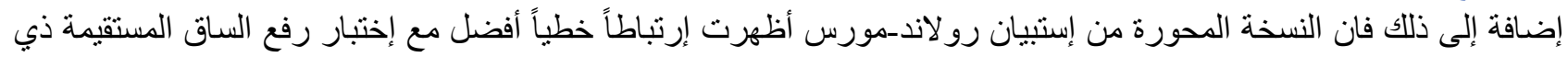

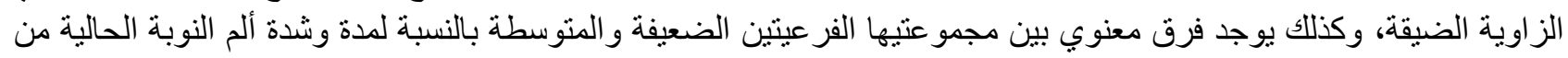

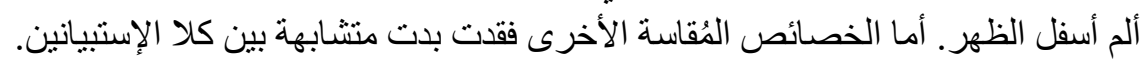
الكلمات المفتاحية: ألم أسفل الظهر، قياس الإعاقة، إستبيان رو لاند- موريس.

\section{INTRODUCTION}

$\mathrm{P}$ ain at lower back is a common problem in everyday practice that reported by the majority of adults during their lifetime and is the most frequent cause of disability for individuals younger than 45 years. It is the third leading cause of disability for those older than 45 years. ${ }^{1,2}$

Acute LBP usually resolves spontaneously, but up to $10 \%$ progresses to chronic LBP resulting in temporary to permanent disability ${ }^{3}$. Chronic nonspecific LBP and its resulting disability have become important epidemic health and a socioeconomic problem ${ }^{4}$.

LBP remains the most important occupational health problem in industrialized countries, accounting for about $20 \%$ to $30 \%$ of workers' compensation claims and up to $50 \%$ of all direct compensation costs ${ }^{5}$.

Disability encompasses impairments, limitations (on activity), and restrictions (to participation) that may occur in the presence of a health condition (disorder or disease) ${ }^{6}$. The LBP results in significant levels of disability, producing substantial restrictions on normal activities and participation, such as an inability to work ${ }^{7}$. Also, the disability is considered as an excellent clinical assessment of severity in $\operatorname{LBP}^{8}$. Several instruments or methods are used to measure disability in LBP. These measures improve our knowledge about the patient functions and the severity of his/her disorders and also can help in following the patient's course $e^{8,9}$. Self-reported questionnaires have become well-accepted measures in assessing disability in patients with LBP ${ }^{10}$.

The Roland-Morris Questionnaire (RMQ) has been frequently used to measure disability in patients with chronic LBP demonstrating good qualities $^{11,12}$. The $R M Q$ which is a self-reported instrument; its questions focus consistently on disabilities related to the back and the answers are dichotomous: yes $/ \mathrm{no}^{13}$. The scores, therefore, range from zero (no disability) to 24 (maximum disability). The questionnaire can complete in a maximum of $5 \mathrm{~min}$, and an un-weighted score can calculate in less than $1 \mathrm{~min}$. No sub-scoring reported, and the administration is straightforward. The questions deal with body functions (pain, sleeping, and appetite) as well as activities (selfcare, walking, sitting, standing, lifting, dressing, stairs climbing, housework and resting) ${ }^{14}$.

The study aimed to evaluate the application of Roland-Morris Disability Questionnaire (RMQ) in its Arabic conversational version, look for correlations or disagreements between RMQ results and other clinical manifestations, particularly, features which 
can predict severity, and suggest modifications to improve the measurement.

\section{METHODS}

The protocol of this study was approved by the Scientific and regional research ethics committees at the College of Medicine in 2014 and by Directorate General of Neneveh Health Department. The study conducted at the rheumatology clinic of Ibn-Sina Teaching Hospital, Mosul, Iraq.

Study Design: Clinical case-series study.

Methods and materials: This study conducted on seventy-two patients after taking their consent to participate in the study with an age range between $(18-60)$ years who suffered from low back pain (LBP) \pm lumbar root symptoms for more than three months.

Exclusion criteria included: Suspicion of neoplastic or infective spinal conditions, compression fractures, chronic inflammatory joint/spinal diseases, organ failure (cardiovascular, respiratory, renal and hepatic), specific neurological problems (stroke, multiple sclerosis, peripheral neuropathy) and pregnancy. Materials included: Mechanical weight and height scale (Fazzini), tape measure, $128 \mathrm{~Hz}$ tuning fork, neurological (reflex) hammer, examination couch, plumb-bob (plummet), electronic stop-watch, and plastic goniometer.

Face to face interviews were performed for patients participated in the study. Demographic, clinical, and other relevant data obtained. The focusing was mainly on the crucial features that have predictive values and included the following:

Buttock pain, below knee pain, the sitting difficulty, Stress pain ${ }^{15-21}$, a history of sciatica longer than three months, decreased lumbar lordosis, painful side bending ${ }^{22,23,24}$ as well as painful forward flexion, positive quadrant test, extension test, neurological deficit of the legs (decreased sensation \& lor power \& /or reflexes), decreased vibration sense at the big toe, scoliosis, limited forward flexion, and limited lateral bending. ${ }^{25-29}$

The pain intensity of the initial episode measured retrospectively on global visual analog scale (VAS) of $(0-100)$ divisions where zero means no pain and 100 means the worst pain, then; this pain intensity subdivided into three subgroups: mild (033), moderate (34-66) and severe (67-100). Pain intensity of the current episode is also measured on VAS and also divided into three subgroups: mild (0-33), moderate (34-66) and severe (67-100).

The presence of scoliosis was assessed by using plumb-bob with the tip of the string placed at the spinous process of the first thoracic vertebra and the weight allowed to hang down to reach the buttock of the patient, if any deviation of the weight from the mid-gluteal cleft observed then the patient reported as having scoliosis ${ }^{30}$.

Flexion of the spine was evaluated by Schober's test ${ }^{31}$. Any increase in the distance of less than 5 $\mathrm{cm}$ considers abnormal. The lateral flexion was assessed using a finger to fibula test, in which the patient asked to bend to one side as much as he can (without any bending forward). The test is considering abnormal if the distance between the tip of the third finger and the head of the fibula was more than $5 \mathrm{~cm}$, then the test repeated on the other side ${ }^{32}$. The extension test is done by asking the patient to actively extend his back as far as tolerated with the examiner providing support for balance, the position held for 30 seconds and the test considered positive if the patient reports pain in the low back area or the lower $\operatorname{limb}^{24}$. While in the quadrant test the patient actively moves into lateral bending, extension, and rotation to the same side as far as tolerated, the examiner guides the patient in this motion and provides overpressure if no pain is reported with this movement.

The test considered positive if the patient reports pain or numbness in the area of the back or lower extremities ${ }^{25}$.

The angle of the SLR test was measured for each patient by the plastic goniometer and subdivided into 3 subgroups: patients with narrow angle SLR (0-45 degree), patients with wide angle SLR (46-70 degree) and patients with negative SLR (more than 70 degree).

Vibration sense as part of the neurological examination for both lower limbs was assessed using a $128 \mathrm{~Hz}$ tuning fork on the medial malleolus and the big toe.

Following a physical examination, the process of answering the twenty-four questions of the RolandMorris Questionnaire (RMQ) was started. Because the level of illiteracy in our community is relatively high, a direct, conversational method was chosen. In this method, the questions of RMQ have answered through face to face investigator-patient 
Arabic conversation. The disability measured by the RMQ subdivided into mild (0-8), moderate (916) and severe (17-24).

After filling the RMQ in its original form, another investigator-patient Arabic conversation started to answer the questions of RMQ in a modified method (RMQV). In this method the answer for each item is obtained on a global visual analogue scales (VAS) of zero to 100 subdivisions. The patient was asked to determine how much his/her various activities (daily living, duties, recreation, and vitality feeling) were affected by each particular question due to the LBP, with zero means no any effect on these activities while 100 indicates the worst outcome that the patient can think of. The disability measured by the RMQV also subdivided into three subgroups: mild (0-30), moderate (31-60) and severe (61-100).

\section{RESULTS}

Seventy-two patients with the history of chronic LBP for more than three months duration participated in this study. Male to female percentage was 41.7: 58.3. As shown in the Table 1 , the mean age and BMl of the studied group were $37.23 \pm 9.14$ and $29.3 \pm 4.46$ respectively.

Table 2 demonstrates the mean duration of LBP (50.31 \pm 52.42 months), initial episode duration (in days), and the initial episode duration (29.16 \pm 37.23 days).

Table 1: Demographic features of the patients.

\begin{tabular}{lc}
\hline Demographic features $($ No.= 72$)$ & \\
\hline Gender & $30(41.7 \%)$ \\
Male & $42(58.3 \%)$ \\
Female & \\
Age: & $19-60 / 37.23( \pm 9.14)$ \\
range/Mean/ $( \pm S D)$ years & $20.9-42.91 / 29.3( \pm 4.46)$ \\
BMI: range/Mean $( \pm S D)$ &
\end{tabular}

Table 2: Different duration categories of LBP and number of the prior episodes.

\begin{tabular}{lccc}
\hline Categories & $\begin{array}{c}\text { Mean } \\
( \pm S D)\end{array}$ & Categories & $\begin{array}{c}\text { Mean } \\
( \pm S D)\end{array}$ \\
\hline $\begin{array}{l}\text { LBP duration } \\
\text { in months }\end{array}$ & $\begin{array}{c}50.31 \\
( \pm 52.42)\end{array}$ & $\begin{array}{c}\text { Current } \\
\text { episode } \\
\text { duration in } \\
\text { days }\end{array}$ & $\begin{array}{c}22.26 \\
( \pm 22.49)\end{array}$ \\
\hline $\begin{array}{l}\text { Initial episode } \\
\text { duration in } \\
\text { days }\end{array}$ & $\begin{array}{c}\text { 29.16 } \\
( \pm 37.23)\end{array}$ & $\begin{array}{c}\text { No. of prior } \\
\text { episodes of } \\
\text { LBP }\end{array}$ & $\begin{array}{c}11.52 \\
( \pm 11.69)\end{array}$ \\
\hline
\end{tabular}

SD = Standard deviation
Table 3 shows the range and mean of the pain intensity for the initial episode of LBP measured on VAS retrospectively and current episodes of LBP measured on VAS. Also range and mean for both $\mathrm{RMQ}$ and RMQV are shown.

Table 4 shows the different subgroups of LBP. In $R M Q$, we can see that the highest percentage of patients $(48.6 \%)$ lie within the moderate subgroup followed by the severe subgroup (26.4\%) and the lowest percentage for the mild subgroup (25\%). In contrast, the distribution of patients within the severity subgroups of RMQV is clearly different, most of the patients lie within the mild subgroup (76.4\%), a small number of patients within the moderate subgroup (19.4\%) and only few number of patients lie within the severe subgroup (4.2\%).

Some of the important clinical features of the patients are shown in the Table 5, including the number and percentage of patients having each particular feature. These clinical features were chosen because they have predictive values.

Table 3: Total pain intensity of initial and current episodes and disability scores.

\begin{tabular}{lc}
\hline $\begin{array}{l}\text { Pain intensity of the initial } \\
\text { episode measured on VAS: } \\
\text { range/mean }( \pm S D)\end{array}$ & $10-100 / 71.52$ \\
$\begin{array}{l}\text { Pain intensity of the current } \\
\text { episode measured on VAS: }\end{array}$ & $20-100 / 59.58$ \\
range/mean $( \pm S D)$ & $( \pm 15.42)$ \\
RMQ score: range/mean $( \pm S D)$ & $2-22 / 12.38( \pm 5.47)$ \\
$R M Q$ score: range/mean & $0-66.67 / 21.71$ \\
$( \pm S D)$ ( & $( \pm 17.26)$ \\
\hline
\end{tabular}

Table 4: Severity subgroups of LBP.

\begin{tabular}{|c|c|c|}
\hline \multicolumn{2}{|c|}{ Severity subgroups } & \multirow{2}{*}{$\begin{array}{c}\text { No. of } \\
\text { patients (\%) } \\
4 / 72(5.6)\end{array}$} \\
\hline Pain intensity of first & Mild & \\
\hline episode measured by & Moderate & 20/72 (27.8) \\
\hline VAS & Severe & $48 / 72(66.7)$ \\
\hline \multirow{3}{*}{$\begin{array}{l}\text { Pain intensity of current } \\
\text { episode measured by } \\
\text { VAS }\end{array}$} & Mild & 1/72 (1.4) \\
\hline & Moderate & $53 / 72(73.6)$ \\
\hline & Severe & 18/72 (25) \\
\hline \multirow{3}{*}{ SLR test subgroups } & $\begin{array}{l}\text { Narrow } \\
\text { angle }\end{array}$ & $15 / 72(20.8)$ \\
\hline & $\begin{array}{l}\text { Wide } \\
\text { angle }\end{array}$ & 23/72 (31.9) \\
\hline & $\begin{array}{l}\text { Negative } \\
\text { test }\end{array}$ & $34 / 72(47.2)$ \\
\hline \multirow{3}{*}{ RMQ subgroups } & Mild & 18/72 (25) \\
\hline & Moderate & $35 / 72(48.6)$ \\
\hline & severe & 19/72 (26.4) \\
\hline \multirow{3}{*}{ RMQV subgroups } & Mild & $55 / 72(76.4)$ \\
\hline & Moderate & 14/72 (19.4) \\
\hline & severe & $3 / 72(4.2)$ \\
\hline
\end{tabular}

$\overline{\mathrm{VAS}}=$ Visual Analogue Scale . 
Table 5: Some of the essential clinical features of the patients.

\begin{tabular}{|c|c|c|c|c|}
\hline \multicolumn{2}{|c|}{ Features } & No. of patients (\%) & Features & No. of patients (\%) \\
\hline \multirow{3}{*}{$\begin{array}{l}\text { Pain } \\
\text { site }\end{array}$} & Lumbar pain & $72 / 72(100)$ & Painful forward flexion & $47 / 72(65.3)$ \\
\hline & Gluteal pain & 33 / 72 (45.8) & Limited lateral bending & $10 / 72(13.9)$ \\
\hline & Below knee pain & $29 / 72(40.3)$ & Painful lateral bending & $41 / 72(56.9)$ \\
\hline \multicolumn{2}{|c|}{ Stress pain } & 34 / 72 (47.2) & Positive extension test & $45 / 72(62.5)$ \\
\hline \multicolumn{2}{|c|}{ Difficulty in sitting } & 49 / $72(68.1)$ & Positive quadrant test & $49 / 72(68.1)$ \\
\hline \multicolumn{2}{|c|}{ History of sciatica $>3$ months } & $9 / 72(12.5)$ & Positive SLR & 38 / $72(52.8)$ \\
\hline \multicolumn{2}{|c|}{ Scoliosis } & $9 / 72(12.5)$ & Neurological deficit of leg & $35 / 72(48.6)$ \\
\hline \multicolumn{2}{|c|}{ Decreased lordosis } & $7 / 72(9.7)$ & Decreased big toe vibration & 19 / $72(26.4)$ \\
\hline \multicolumn{2}{|c|}{ Limited forward flexion } & $9 / 72(12.5)$ & & \\
\hline
\end{tabular}

The total number of positive clinical features with predictive values (16 features) for each patient was estimated and, the resulting total score of these predictive features (which ranged from 0-16) was compared with that of the RMQ and RMQV separately. The range and mean of this predictive features-score were $(0-15)$ and $6.43 \pm 2.83$ respectively. Table 6 shows the correlation between the predictive features score and each of $\mathrm{RMQ}$ and RMQV.

Table 7 compares between the means for $\mathrm{RMQ}$ and RMQV questionnaires according to Pearson correlation coefficient and independent samples ttest. Both of them were significant.

Table 8 shows the proportions of patients for each particular clinical feature within the severity subgroups of the RMQV. The comparison between the percentages of patients having each particular clinical feature within the mild and moderate subgroups of the RMQV has been studied using the two-proportion test. If the number of patients for a specific clinical feature was zero in the mild and/or the moderate subgroups, then the percentage of patients for this feature is not compared. Statistical analysis of the severe subset of the RMQV was omitted because of the small number of patients in this subgroup (3 patients only).

Table 6: Correlation (Pearson's coefficient $r$ ) between predictive features score and the disability scores (RMQV and RMQ).

\begin{tabular}{lcc}
\hline \multirow{2}{*}{ Predictive } & \multicolumn{2}{c}{ Pearson's coefficient $(\boldsymbol{r})$} \\
\cline { 2 - 3 } features score & RMQV & RMQ \\
P-value & 0.530 & 0.503 \\
\hline
\end{tabular}

Table 7: The Cronbach's alpha, Pearson's correlation coefficient ( $r$ ) and comparison between the means for both $\mathrm{RMQ}$ and $\mathrm{RMQV}$.

\begin{tabular}{lccc}
\hline $\begin{array}{l}\text { Disability } \\
\text { score }\end{array}$ & $\begin{array}{c}\text { Independent } \\
\text { samples t- } \\
\text { test }\end{array}$ & $\begin{array}{c}\text { Pearson's } \\
\text { correlation } \\
\text { coefficient }(r)\end{array}$ & $\begin{array}{c}\text { Cronbach's } \\
\text { alpha }\end{array}$ \\
\hline RMQ & $P<0.01$ & 0.861 & $\begin{array}{c}0.72 \\
\text { (acceptable } \\
\text { reliability) } \\
0.94 \\
\text { (excellent } \\
\text { reliability) }\end{array}$ \\
\hline
\end{tabular}

Table 8: Numbers and percentages of patients having some particular clinical features within RMQV subgroups.

\begin{tabular}{|c|c|c|c|c|}
\hline \multicolumn{2}{|c|}{ Clinical features } & $\begin{array}{c}\text { Mild } \\
55 / 72 \\
(\%)\end{array}$ & $\begin{array}{l}\text { Moderate } \\
14 / 72(\%)\end{array}$ & $\begin{array}{c}\mathrm{p}- \\
\text { value }\end{array}$ \\
\hline \multirow{3}{*}{$\begin{array}{l}\text { Pain } \\
\text { intensity } \\
\text { of the } \\
\text { current } \\
\text { episode }\end{array}$} & & $1(1.8)$ & 0 & NC \\
\hline & Moderate & $47(85.5)$ & $6(42.9)$ & 0.002 \\
\hline & Severe & $7(12.7)$ & $8(57.1)$ & 0.001 \\
\hline \multicolumn{2}{|c|}{ Buttock pain } & $21(38.2)$ & $9(64.3)$ & NS \\
\hline \multicolumn{2}{|c|}{ Below knee pain } & $22(40)$ & $5(35.7)$ & NS \\
\hline \multicolumn{2}{|c|}{ Stress pain } & $19(34.5)$ & $12(85.7)$ & $<0.001$ \\
\hline \multicolumn{2}{|c|}{ Difficulty in sitting } & $36(65.5)$ & $10(71.4)$ & NS \\
\hline \multicolumn{2}{|c|}{$\begin{array}{l}\text { Prior sciatica }>3 \\
\text { months }\end{array}$} & $7(12.7)$ & $1(7.1)$ & NS \\
\hline \multicolumn{2}{|c|}{ Scoliotic posture } & $5(9.1)$ & $2(14.3)$ & NS \\
\hline \multicolumn{2}{|c|}{ Decreased lordosis } & $4(7.3)$ & $2(14.3)$ & NS \\
\hline \multicolumn{2}{|c|}{$\begin{array}{l}\text { Limited forward } \\
\text { flexion }\end{array}$} & $4(7.3)$ & $3(21.4)$ & NS \\
\hline \multicolumn{2}{|c|}{$\begin{array}{l}\text { Painful forward } \\
\text { flexion }\end{array}$} & $34(61.8)$ & $11(78.6)$ & NS \\
\hline \multicolumn{2}{|c|}{$\begin{array}{l}\text { Limited lateral } \\
\text { bending }\end{array}$} & $6(10.9)$ & $1(7.1)$ & NS \\
\hline \multicolumn{2}{|c|}{$\begin{array}{l}\text { Painful lateral } \\
\text { bending }\end{array}$} & $27(49.1)$ & $11(78.6)$ & 0.022 \\
\hline \multicolumn{2}{|c|}{$\begin{array}{l}\text { Positive quadrant } \\
\text { test }\end{array}$} & $36(65.5)$ & $10(71.4)$ & NS \\
\hline \multicolumn{2}{|c|}{$\begin{array}{l}\text { Positive extension } \\
\text { test }\end{array}$} & $33(60)$ & $10(71.4)$ & NS \\
\hline \multicolumn{2}{|c|}{ Positive SLR } & $26(47.3)$ & $10(71.4)$ & NS \\
\hline \multicolumn{2}{|c|}{$\begin{array}{l}\text { Neurological deficit } \\
\text { of leg }\end{array}$} & $24(43.6)$ & $8(57.1)$ & NS \\
\hline \multicolumn{2}{|c|}{$\begin{array}{l}\text { Decreased big toe } \\
\text { vibration }\end{array}$} & $13(23.6)$ & $4(28.6)$ & NS \\
\hline
\end{tabular}


Table 9 shows the proportions of patients for each particular clinical feature within the severity subgroups of the RMQ. The comparisons between the percentages of patients having each particular clinical feature within the mild and moderate subgroups of the RMQ have been studied using the two-proportions z-test. If the number of patients for a particular clinical feature was found to be zero in the mild and/or the moderate subgroups, then the percentage of patients for that feature has not been compared. A comparison with the severe subgroup was not performed as it has not been performed in that of the RMQV one (the preceding table).

Table 10 shows the different duration categories of LBP for each severity subgroup of the RMQV and RMQ. Statistical analysis between the severe subgroups of the RMQ and RMQV was omitted because of the small number of patients in the severe subgroup of RMQV (3 patients only).

Table 9: Numbers and percentages of patients having some particular clinical features within RMQ subgroups.

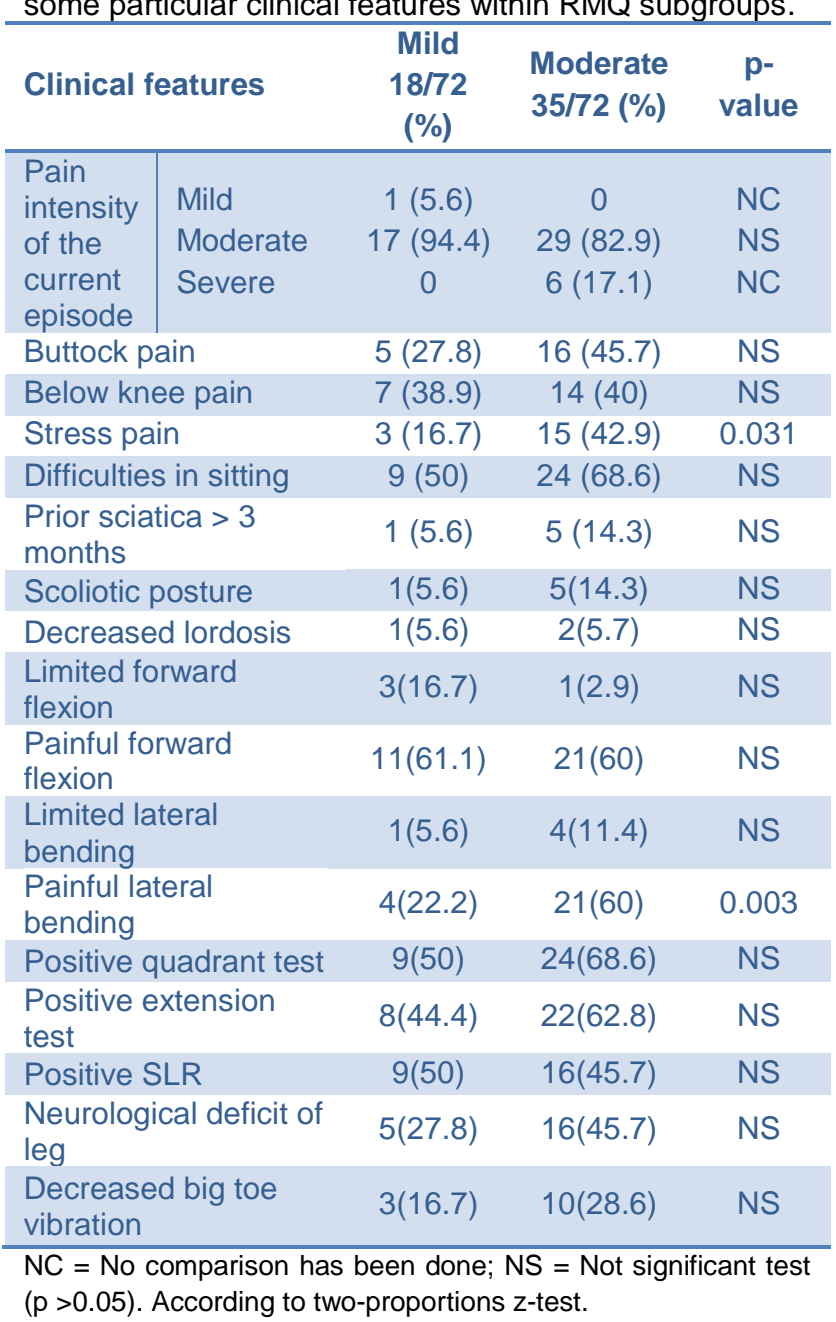

Table 11 shows the correlations between the severity subgroups of both (RMQ and RMQV) and the pain intensity of the current episode of LBP (Pearson's correlation), and between the severity subgroups of both RMQ and RMQV, and the SLR test subgroups (Spearman's rank correlation).

Table 10: Different duration categories for each severity subgroups of $R M Q$ \& RMQV.

\begin{tabular}{|c|c|c|c|c|c|c|}
\hline $\begin{array}{c}\text { Severity } \\
\text { subgroups }\end{array}$ & \multicolumn{2}{|c|}{$\begin{array}{c}\text { Duration } \\
\text { since onset in } \\
\text { months: } \\
\text { mean }( \pm S D)\end{array}$} & \multicolumn{2}{|c|}{$\begin{array}{l}\text { Initial episode } \\
\text { duration in } \\
\text { days: mean } \\
\text { ( } \pm S D)\end{array}$} & \multicolumn{2}{|c|}{$\begin{array}{l}\text { Current } \\
\text { episode } \\
\text { duration in } \\
\text { days: mean } \\
( \pm S D)\end{array}$} \\
\hline Mild RMQV & $\begin{array}{c}49.34 \\
( \pm 53.01)\end{array}$ & \multirow[b]{2}{*}{ NS } & $\begin{array}{c}24.58 \\
( \pm 28.41)\end{array}$ & \multirow[b]{2}{*}{ NS } & $\begin{array}{c}18.56 \\
( \pm 18.2)\end{array}$ & \multirow[b]{2}{*}{$\mathrm{S}^{* *}$} \\
\hline $\begin{array}{l}\text { Moderate } \\
\text { RMQV }\end{array}$ & $\begin{array}{c}44.35 \\
( \pm 41.57)\end{array}$ & & $\begin{array}{c}34.28 \\
( \pm 25.3)\end{array}$ & & $\begin{array}{c}39.78 \\
( \pm 30.8)\end{array}$ & \\
\hline Mild RMQ & $\begin{array}{c}44.94 \\
( \pm 63.38)\end{array}$ & & $\begin{array}{c}30.94 \\
( \pm 41.05)\end{array}$ & & $\begin{array}{c}17.88 \\
( \pm 16.82)\end{array}$ & \\
\hline $\begin{array}{l}\text { Moderate } \\
\mathrm{RMQ}\end{array}$ & $\begin{array}{c}51.34 \\
( \pm 49.1)\end{array}$ & NS & $\begin{array}{c}18.94 \\
( \pm 16.79)\end{array}$ & NS & $\begin{array}{c}15.97 \\
( \pm 15.28)\end{array}$ & NS \\
\hline $\begin{array}{l}\text { Severe } \\
R M Q\end{array}$ & \multicolumn{2}{|c|}{$53.52( \pm 49.5)$} & \multicolumn{2}{|c|}{$46.31( \pm 53.18)$} & \multicolumn{2}{|c|}{$38( \pm 30.47)$} \\
\hline
\end{tabular}

$\mathrm{S}^{* *}=$ significant difference at $\mathrm{p}$-value $<0.01 ; \mathrm{NS}=$ not significant (using independent samples t-test $(>0.05)$.

Table 11: Correlations between subgroups of pain intensity and SLR test with that of RMQV and RMQ.

\begin{tabular}{lcc}
\hline Features & $\begin{array}{c}\text { RMQV } \\
\text { subgroups }\end{array}$ & $\begin{array}{c}\text { RMQ } \\
\text { subgroups }\end{array}$ \\
\hline $\begin{array}{l}\text { Pain intensity } \\
\text { subgroups }\end{array}$ & $0.634^{* *}(r)$ & $0.625^{* *}(r)$ \\
$\begin{array}{l}\text { SLR degree } \\
\text { subgroups }\end{array}$ & $0.262^{*}($ rho $)$ & 0.154 (rho) \\
\hline $\begin{array}{l}\text { * }=\text { P-value }<0.05 ;{ }^{* *}= \\
\text { coefficient. } \\
\text { rho }=\text {-value }<0.01, r=\text { Pearman's rank correlation coefficient. }\end{array}$
\end{tabular}

\section{DISCUSSION}

The self-reported questionnaires of disability are of great relevance in assessing the severity of low back pain (LBP). The Roland-Morris Questionnaire (RMQ) is considered one of the most commonly studied self-reported disability measures ${ }^{8,33}$. This questionnaire is considered thoroughly validated, have acceptable reliability and is recommended and referred to as a tool of choice in the assessment of the severity of disability caused by LBP ${ }^{34}$. Also, it is quickly completed, easy to be understood and scored, and broadly consistent with the WHO ICF definition of activity limitation.

But among the weakening points of this questionnaire are: being purely subjective and lack any physical signs, dichotomous responses only with no ability to rate the degree of limitation for a 
given functional activity, providing equal marks to mild and severe symptoms, patients rate limitation just in last 24 hours, depends mainly on daily living activities rather than duties and work activities (such as lifting, carrying, pushing or pulling objects) ${ }^{35,36}$. Moreover, the high levels of illiteracy in many countries make the completion of such self-reported questionnaire by the patient alone very difficult. Therefore in this study, an Arabic conversational version of the RMQ was chosen, which has been adapted in the rheumatology unit of Ibn-Sina teaching hospital.

The mean age of seventy-two participated patients was 37.23 years, and this is within the range of age considered to have the highest frequency of LBP ${ }^{37}$. Their mean BMI was also high $\left(29.3 \mathrm{~kg} / \mathrm{m}^{2}\right)$ and the high BMI is considered as a risk factor for chronicization of acute and subacute LBP ${ }^{20}$. The mean duration of LBP since its initial onset was 50.31 months and the mean duration of the initial episode of LBP was 29.16 days; whereas the mean duration of the current episode of LBP was 22.26 days. All the patients were having a history of more than one previous episode of LBP with the mean number equal to 11.52 episodes.

The mean intensity of the pain for initial episodes measured on global VAS scale (0-100 scores) was (71.52/out of 100 scores) and, there were 4 patients $(5.6 \%)$ having mild pain, 20 patients $(27.8 \%)$ having moderate pain and, 48 patients $(66.7 \%)$ having severe pain. The mean intensity of the current episode pain which also measured on global VAS scale was 59.58 and, there was only one patient $(1.4 \%)$ having mild pain, 53 patients $(73.6 \%)$ having moderate pain and 18 patients $(25 \%)$ having severe pain. The range and mean for $\mathrm{RMQ}$ were 2- 22 and 12.38 respectively; and there were 18 patients $(25 \%)$ lie within its mild subgroup, 35 patient $(48.6 \%)$ within its moderate subgroup, and nineteen patients (26.4\%) within the severe subgroup. While for RMQV the range and mean were $0-66.67$ and 21.71 respectively; and there were 55 patients $(76.4 \%)$ lie within its mild subgroup, 14 patients (19.4\%) within its moderate subgroup, and only 3 patients $(4.2 \%)$ within the severe subgroups. The mean scores for the RMQ reflect a moderate level of disability while that for the $\mathrm{RMQV}$ reflect a mild degree of disability.
It appears that the differences in the distribution of patients within the severity subgroups of RMQ and RMQV are remarkable. Most patients lie within the mild subgroup of the RMQV and a minimal number within the severe one, while most of the patients lie in the moderate subgroup of $\mathrm{RMQ}$ followed by the severe, then the mild ones. These may indicate that a high percentage of the patients who considered to have moderate or severe disabilities according to the RMQ was really only mildly disabled according to the RMQV. Therefore these two questionnaires are different from each other, and this difference was confirmed by comparing the means for both questionnaires using independent samples t-test which showed a significant difference between them ( $p$-value< 0.01 ). Yet they were found to have a strong direct correlation with each other $(r=0.861 ; p$-value $<$ $0.001)$. The reliability for the Arabic conversational version of the RMQ was estimated using Cronbach's alpha, and it was 0.73 , and for the $\mathrm{RMQV}$ the reliability was higher (Cronbach's alpha $=0.94$ ).

What we call them predictive features are actually predict various aspects in LBP, like unresponsiveness to physical medicine modalities $17,18,38$, chronicity ${ }^{19,20,23}$, poor or unfavorable outcome $^{21,24,25,28}$, severity ${ }^{26,29,30}$, and the presence of underlying nerve root compression or disc protrusion $^{22,32}$.

Collectively, these predictive features have an impact on the management of patients with LBP.

A set of clinical features (16 features) with predictive and prognostic values was used for comparison with both $R M Q$ \& RMQV separately. The total numbers of positive predictive features were estimated for each patient, and the final score was used to compare it with that of $\mathrm{RMQ}$ and RMQV for the same patient.

The correlation between these predictive features score and each of the RMQ and RMQV were found to be moderate and significant $(r=0.503, p$-value $<0.01$ and $r=0.530, p$-value $<$ 0.01 respectively). The number and percentages of patients having each particular clinical feature in each severity subgroup of the RMQ and RMQV were estimated. The two-proportion test was used to compare the percentages of patients having each of these clinical features in the mild subgroup and those having the same clinical features in the 
moderate subgroup of the RMQV. The same comparisons also performed for the patients within the mild and moderate subgroups of the RMQ. The results revealed that there were significant differences between the mild and moderate subgroups of RMQV in the frequency of stress pain and painful lateral bending ( $p$-value $<0.001$ and $<0.05$ respectively). Similar results occurred between mild and moderate subgroups of RMQ ( $p$ value $=0.03$ and 0.003 respectively). Furthermore, the moderately severe current back pain episode was significantly more common in the mild RMQV subgroup ( $p$-value $=0.002$ ); while the severe current episode was significantly more common in the moderate RMQV subgroup ( $p$-value $=0.001$ ). In the $R M Q$, on the other hand, the severity of current back pain episode was not different between mild and moderate subgroups. There were no significant differences between the percentages of patients with the remaining clinical features in both the RMQ and RMQV.

The mean duration of LBP since its onset was found to be longer in the mild subgroup (49.34 months) than the moderate subgroup (44.35 months) of the RMQV, while it was longer in the moderate (51.34 months) than the mild subgroups (44.94 months) of the RMQ. The mean duration of the initial episodes was found to be longer in the moderate subgroup (34.28 days) than in the mild one (24.58 days) in the RMQV, while it was longer in the mild (30.94 days) than the moderate subgroups (18.94 days) of the RMQ. In case of the current episode, its mean duration was found to be longer in the moderate subgroups (39.78 days) than in the mild one (18.56 days). Also, its mean duration was longer in the mild (17.88 days) than the moderate subgroups (15.97 days) of the RMQ. These differences in the duration categories were found to be significant only for the mean duration of the current episode of LBP between the severity subgroups of RMQV with p-value $<0.01$ (using independent samples t-test).

Furthermore, the intensity of the LBP was found to have strong correlations with $R M Q$ and $R M Q V$ $(r=0.625$ at $p$-value $<0.01$ and $r=0.634$ at $p$-value $<0.01$ respectively). The pain intensity of the LBP considered having predictive values such as being a predictor of short-term outcome after lumbar discectomy ${ }^{39}$, also it is considered to be correlated with greater disability in patients with lumbar spinal stenosis ${ }^{40}$.

A narrow angle SLR test also has predictive values such as being a predictor of poor outcome after lumbar disc herniation surgery ${ }^{41}$. Spearman's rank correlation was used to compare the severity subgroups of both the RMQ and RMQV with the SLR test subgroups, a significant moderate correlation was found between the SLR test subgroups and the RMQV subgroups ( $\mathrm{rho}=0.262$ at $p$-value $<0.05$ ), whereas the relationship between the SLR test subgroups and the RMQ subgroups was weak and not significant (rho $=$ 0.154).

\section{CONCLUSIONS}

Arabic translation and face to face interview instead of the original patient report can maintain the excellent internal consistency of the questionnaires.

The differences between the original RMQ and the VAS-graded modification (RMQV) are prominent in that the RMQV have better reliability, better correlation with the narrow-angle straight leg raising test, and its mild and moderate subgroups have significant differences regarding the duration and pain intensity of the current episode of low back pain.

The scores of the two versions RMQ correlated somewhat moderately with the predictive and prognostic clinical feature.

\section{REFERENCES}

1. Dunn KM, Croft PR. Epidemiology and natural history of low back pain. Eur med phys 2004;40:9-13.

2. Wildstein MS and Carragee EJ. Low Back Pain. In: Firestein GS, Budd RC, Harris Jr ED, Mclnnes IB, Ruddy $S$, Sergent JS (eds) Kelley's Textbook of Rheumatology, eighth edition. 2009. Sunders Elsever. Philadelphia, $p$ 617.

3. Whiteman HH, Clauw DJ, Beary JF. Low Back Pain. In: Paget SA, Gibofsky A, Beary JF, Sculco TB (eds) Hospital for Special Surgery Manual of Rheumatology and Outpatient Orthopedic Disorders: Diagnosis and Therapy, fifth edition. 2006. Lippincott Williams \& Wilkins. Philadelphia, p 145-147.

4. Smeets RJ, Vlaeyen JW, Hidding A, Kester AD, van der Heijden GJ, Knottnerus JA . Chronic low back pain: physical training, graded activity with problem solving training, or both? The one-year post-treatment results of a randomized controlled trial. Pain 2008;134:263-276.

5. Kerr MS, Frank JW, Shannon HS, Norman RW, Wells RP, Neumann WP, et al. Biomechanical and psychosocial risk factors for low back pain at work. Am J Public Health 2001;91(7):1069-75. 
6. Rondinelli RD. Disability Determination. In: Delisa JA, Gans BM, Walsh NE, Bockenek WL, Frontera WR, Geiringer SR, et al. (eds) Physical Medicine \& Rehabilitation: Principles and Practice, fourth edition. 2005. Lippincott Williams \& Wilkins, p 170-171.

7. Louw QA, Morris LD, Grimmer-Somers K. The prevalence of low back pain in Africa: a systematic review. BMC Musculoskelet Disord. 2007; 8:105.

8. Mannion AF, Dvorak J, Müntener M, Grob D. A prospective study of the interrelationship between subjective and objective measures of disability before and 2 months after lumbar decompression surgery for disc herniation. Eur Spine J. 2005;14(5):454-65.

9. Stratford PW, Binkley JM. Applying the results of selfreport measures to individual patients: an example using the Roland-Morris Questionnaire. J Orthop Sports Phys Ther. 1999;29(4):232-9.

10. Cai C, Pua YH, Lim KC. Correlates of self-reported disability in patients with low back pain: the role of fearavoidance beliefs. Ann Acad Med Singapore 2007; 36(12):1013-20.

11. Beurskens AJ, de Ver HC, Koke AJ, van der Heijden GJ, Knipschild PG. Measuring the functional status of patients with low back pain. Assessment of the quality of four disease-specific questionnaires. Spine (Phila pa 1976), 1995;20(9):1017-28.

12. Calmels $P$, Bethoux $F$, Condemine $A$, Fayolle-Minon I. Low back pain disability assessment tools. Ann Readapt Med Phys. 2005;48(6):288-97.

13. Roland M, Morris R. A study of the natural history of back pain. Part I: development of a reliable and sensitive measure of disability in low-back pain. Spine (Phila Pa 1976), 1983; 8(2):141-4.

14. Muller U, Duetz MS, Roeder C, Greenough CG. Condition-specific outcome measures for low back pain Part 1: Validation. Eur Spine J 2004 a ;13(4):301-313.

15. Fritz JM, Whitman JM, Flynn TW, Wainner RS, Childs JD. Factors related to the inability of individuals with low back pain to improve with a spinal manipulation. Phys Ther. 2004;84(2):173-90.

16. Childs JD, Fritz JM, Flynn TW, Irrgang JJ, Johnson KK, Majkowski GR. A clinical prediction rule to identify patients with low back pain most likely to benefit from spinal manipulation: a validation study. Ann Intern Med. 2004;141(12):920-8.

17. Valat JP, Goupille $P$, Védere V. Low back pain: risk factors for chronicity. Rev Rhum Engl Ed 1997; 64(3): 189-94. (abstract)

18. Negrini S, Fusco C, Atanasio S, Romano M, Zaina F. low back pain: state of art. European Journal of Pain Supplements 2008;2:52-56.

19. Vroomen PC, de Krom MC, Knottnerus JA. Predicting the outcome of sciatica at short-term followup. Br J Gen Pract 2002 a; 52(475):119-23.

20. Vroomen PC, de Krom MC, Wilmink JT, Kester AD, Knottnerus JA. Diagnostic value of history and physical examination in patients suspected of lumbosacral nerve root compression. J Neurol Neurosurg Psychiatry 2002 b; 72(5):630-4.

21. Thomas E, Silman AJ, Croft PR, Papageorgiou AC, Jayson MI, Macfarlane GJ. Predicting who develops chronic low back pain in primary care: a prospective study. BMJ 1999;318(7199):1662-7.
22. Schoeggl A, Maier $H$, Saringer W, Reddy M, Matula C. Outcome after chronic sciatica as the only reason for lumbar microdiscectomy. J Spinal Disord Tech 2002; 15(5):415-9.

23. Nykvist $F$, Alaranta $H$, Hurme M, Karppi SL. Clinical findings as outcome predictors in rehabilitation of patients with sciatica. Int J Rehabil Res 1991;14(2):13144.

24. Katz JN, Dalgas M, Stucki G, Katz NP, Bayley J, Fossel $\mathrm{AH}$ et al. Degenerative lumbar spinal stenosis. Diagnostic value of the history and physical examination. Arthritis Rheum. 1995;38(9):1236-41.

25. Lyle MA, Manes S, McGuinness M, Ziaei S, Iversen MD. Relationship of physical examination findings and self-reported symptom severity and physical function in patients with degenerative lumbar conditions. Phys Ther. 2005;85(2):120-33.

26. Grotle M, Brox JI, Veierød MB, Glomsrød B, Lønn $\mathrm{JH}$, Vøllestad NK. Clinical course and prognostic factors in acute low back pain: patients consulting primary care for the first time. Spine (Phila Pa 1976). 2005;30(8):97682.

27. Lin SI, Lin RM. Disability and walking capacity in patients with lumbar spinal stenosis: association with sensorimotor function, balance, and functional performance. J Orthop Sports Phys Ther 2005; 35(4):220-6.

28. Michel A, Kohlmann T, Raspe $H$. The association between clinical findings on physical examination and self-reported severity in back pain. Results of a population-based study. Spine (Phila Pa 1976), 1997; 22(3): 296-303.

29. Kerr RS, Cadoux-Hudson TA, Adams CB. The value of accurate clinical assessment in the surgical management of the lumbar disc protrusion. J Neurol Neurosurg Psychiatry. 1988;51(2):169-73.

30. Levine DB, Leipzig JM. The Painful Back. In: McCarty DJ, Koopman WJ (eds). Arthritis and Allied Conditions. A Textbook of Rheumatology, twelfth edition. 1993. Lee \& Febiger. London, p 1586.

31. Schober's test - Wikipedia. Found in: https://en.wikipedia.org/wiki/Schober\%27s test.

32. Schned ES. Ankylosing Spondylitis. In: (eds) Hospital for Special Surgery Manual of Rheumatology and Outpatient Orthopedic Disorders: Diagnosis and Therapy, fifth edition. 2006. Lippincott Williams \& Wilkins. Philadelphia, p 309.

33. Riddle DL, Stratford PW, Binkley JM. Sensitivity to change of the Roland-Morris Back Pain Questionnaire: part 2. Phys Ther 1998;78(11):1197-207.

34. Björklund $M$, Hamberg J, Heiden M, BarnekowBergkvist $M$. The assessment of symptoms and functional limitations in low back pain patients: validity and reliability of a new questionnaire. Eur Spine J. 2007;16 (11):1799-811.

35. Peat G. PPA recommendation for low back painrelated functional limitation outcome measures. The Chartered Society of Physiotherapy. 2004. Found in: https://www.csp.org.uk.

36. Davidson M. Rasch analysis of 24-, 18- and 11-item versions of the Roland-Morris Disability Questionnaire. Qual Life Res. 2009;18 (4):473-81.

37. Manchikanti L. Epidemiology of Low Back Pain. Pain Physician 2000;3(2)167-192. 
38. Hicks GE, Fritz JM, Delitto A, McGill SM. Preliminary development of a clinical prediction rule for determining which patients with low back pain will respond to a stabilization exercise program. Arch Phys Med Rehabil. 2005;86(9):1753-62.

39. Moranjkic $M$, Ercegovic $Z$, Hodzic $M$, Brkic $H$. Outcome Prediction in Lumbar Disc Herniation Surgery. Acta Medica Saliniana 2010;39(2):75-80.
40. Lin SI, Lin RM, Huang LW. Disability in patients with degenerative lumbar spinal stenosis. Arch Phys Med Rehabil. 2006;87(9):1250-6.

41. Jönsson $B$, Strömqvist $B$. The straight leg raising test and the severity of symptoms in lumbar disc herniation. A preoperative evaluation.Spine. 1995; 20(1):27-30. 